\title{
The Africa Region Misses the Deadline for the Millennium Development Goals: What Now? Kebogile E Mokwena
}

Department of Public Health, Sefako Makgatho Health Sciences University, South Africa

\section{Short Communication}

The current year sees the deadline for the Millennium Development Goals (MDGs), and there is cause for applause for those regions and countries which set goals and were able to achieve them. However, most African countries were not able to reach their goals, and this paper aims to consider this 'failure' in the context of the African region, and to consider lessons learnt which will be of value for the future of development programs for Africa. As a region, Africa faces many challenges, including limited human and financial resources, regional conflict and poor governance. A major factor that worked against the ability to reach the MDGs in Africa is under-development in many areas of the continent.

Health-related MDGs require the implementation of public health interventions, which has certain pre-requisites as set out by the Ottawa Charter for Health Promotion [1]. The lack of these prerequisites (peace, shelter, education, food, income, a stable eco-system, sustainable resources, social justice, and equity) implies that the region started on a back foot while attempting to meet the MDGs, hence the failure to reach stated goals. Actually, Easterly [2] argued that from the beginning of the MDG countdown, it was predicted and reported by several authors, that the goals are not reachable for many African countries. This is because the achievement of the MDGs depended on, amongst others, health infrastructure, policies for monitoring and evaluating, human and financial resources and public health activism, which remain challenging for many countries in the African region. Instead, between 2000 and 2008, substantial increases in mortality and morbidity were recorded in South Africa [3] as well as other African countries. There is therefore a view that the African region was set up for failure in reaching the MDGs in their current form and when using the stated indicators.

Although the MDGs focus on promoting human development, it is that very development base that determines the extent to which further development can be attained. According to the rankings of the United Nations' Human Development Index (HDI), there is wide underdevelopment in the African region. None of the African countries feature in the very high rankings, only 4 feature in high ranking and the least developed category consists mostly of African countries. The factors that have contributed to the lagging behind in development continue to negatively impact on reaching the set MDGs. One of the contributory enablers to the goals was financial aid to the Africa region, which experienced challenges because of a decline in the overseas development assistance by rich countries [4-7]. The ability to provide the assistance pledged to African countries to help them achieve the MDGs was further compromised by the global economic slump of 2008 $[8,9]$.

Despite this apparent failure, and contrary to MDG progress reports on Africa, [10,11] are of the view that, considering where African countries were at the beginning of the countdown, as well as contextualizing identified challenges that impact on the ability to achieve the MDGs, African countries have actually out-performed global averages in progress to achieving the MDG targets. There is also an argument that the measurement method used has disadvantaged African countries and make them look worse than they really are [12]. An alternative method and a different metric is recommended, which will probably have different conclusions about the African continent and the MDGs.

Despite these and other arguments, the MDG program was valuable for the African region, to the extent that it enabled the region to identify its health and development inefficiencies, and to set its goals. Post 2015, the program should be further used to focus on the non-achieved goals and continue to work towards them because the need to address the identified health, social and development matters remain. Post 2015, the value of the MDG program still remains, i.e. as a process to assist in improving and monitoring the efficiency of public health and social programs, research and training programs. From the attempts and efforts to achieve the MDGs, major lessons learnt include the following:

1. The need to prioritise programs because in resource limited settings as is experienced in the African region, it is difficult to spread resources to focus on all the goals with the same intensity at the same time. African countries need to identify urgent matters that should be regarded as pre-requisites, which will act as enablers for further development.

2. The need to set realistic and achievable goals, informed by available infrastructure and the political climate.

3. The need to set mechanisms to achieve the set goals. Achieving each set goal requires a change in attitude, policy and practice.

4. Inform human resources training needs because the goals require changes in previous practices.

5. Identify research focus areas which are based on the situation of each country.

6. Health service funding, which is the corner stone of health services

7. Learning from each other, because African countries have a lot in common.

In conclusion, in order to obtain maximum benefit from this program, the Africa region needs to revisit its goals, revisit indicators, allocate resources and re-focus health services.

${ }^{*}$ Corresponding author: Kebogile E Mokwena, Department of Public Health Sefako Makgatho Health Sciences University, South Africa, Tel: 2712521 4613; E-mail: Kebogile_mokwena@embanet.com

Received August 03, 2015; Accepted August 17, 2015; Published August 24, 2015 Citation: Mokwenal KE (2015) The Africa Region Misses The Deadline For The Millennium Development Goals: What Now?. J Trop Dis 3: 174 doi:10.4174/2329891X.1000174

Copyright: @ 2015 Mokwenal KE.This is an open-access article distributed under the terms of the Creative Commons Attribution License, which permits unrestricted use, distribution, and reproduction in any medium, provided the original author and source are credited. 
Citation: Mokwenal KE (2015) The Africa Region Misses The Deadline For The Millennium Development Goals: What Now?. J Trop Dis 3: 174. doi:10.4174/2329891X.1000174

Page 2 of 2

\section{Reference}

1. World Health Organization (1986) Ottawa Charter for Health Promotion.

2. Easterly W (2009) How the millennium development goals are unfair to Africa World Development 37: 26-35.

3. Chopra M, Lawn JE, Sanders D, Barron P, Karim SSA, et al. (2009) Achieving the health Millennium Development Goals for South Africa: challenges and priorities. The Lancet 374: 1023-1031.

4. Bond P (2006) Global governance campaigning and MDGs: From top-down to bottom-up anti-poverty work. Third World Quarterly 27: 339-354.

5. Bourguignon $F$ and Sundberg M (2006) Constraints to achieving the MDGs with scaled-up aid. UN Department of Economic and Social Affairs Working Paper 15.

6. Clemens MA, Kenny CJ and Moss TJ (2007) The trouble with the MDGs: confronting expectations of aid and development success. World development
35: 735-751.

7. United Nations Development Programme (2014) Human Development Report.

8. Buss PM (2009) Public health and the world economic crisis. Journal of epidemiology and community health $63: 417-417$.

9. Maathai W (2011) Challenge for Africa. Sustainability Science 6: 1-2.

10. Fukuda-Parr S (2008) Are the MDGs priority in development strategies and aid programmes? Only few are! (No. 48). Working Paper International Poverty Centre.

11. Clemens MA, Kenny CJ, Moss TJ (2007). The trouble with the MDGs: confronting expectations of aid and development success. World development 35: 735-751.

12. MDG Progress Reports- Africa (2014) The MDG Report: Assessing Progress in Africa Toward the Millennium Development Goals. 